\title{
A Note on Anesthetically-Induced Frightening "Near-Death Experiences"
}

Kenneth Ring, Ph.D. University of Connecticut

ABSTRACT. Previously (Ring, 1994a, 1994b) I had speculated that the "meaningless void" type of frightening near-death experience (NDE), in which the individual finds him- or herself in a situation of existential nullity in which life itself is understood to be an illusion or a cruel joke, indicating that nothing has any inherent meaning or reality, tends to occur following the use of anesthetics, and is more likely to be reported by women. I present here empirical evidence from medical studies of reactions to nitrous oxide, which corroborate both of those speculations. In light of these findings, I believe that this type of experience is best regarded, despite its subjective reality and long-lasting effects, as an emergence reaction triggered by drugs, and not as a true NDE.

On a recent trip to Colorado, I met with a woman who, when she was 13 , had a very frightening experience in connection with a routine tonsillectomy during which she had, of course, received an anesthetic. Now in her early 50s, she confessed to me that this experience had haunted her ever since, resulting, she said, in a persisting fear of death and a history of panic attacks. As a result of these concerns, she had taken the trouble to investigate some of the literature on the anesthesiology of emergence reactions, and in the course of that search had received a miscellany of articles and reprints from a specialist, James Zacny, on the effects of nitrous oxide.

Kenneth Ring, Ph.D., is Professor Emeritus of Psychology at the University of Connecticut. Reprint requests should be addressed to Dr. Ring at the Department of Psychology, 406 Babbidge Road, U-20, University of Connecticut, Storrs, CT 062691020. 
Before I left for Connecticut, she gave me copies of her collection of papers and, on the flight home, I read through them.

Doing so, I found that she had inadvertently provided me with something of a gold mine for my earlier speculations (Ring, 1994a, 1994b) about a certain type of frightening near-death experience (NDE), namely the kind of encounter that I had labeled "the meaningless void," paraphrasing the the terms used by Bruce Greyson and Nancy Evans Bush (1992) in their pioneering study of distressing NDEs. In this variety of frightening NDE, the individual finds himor herself in a situation of existential nullity, seemingly without end, in which life itself is understood to be an illusion or a kind of cruel cosmic joke, indicating that nothing has any inherent meaning or reality. Naturally, these revelations are profoundly disturbing to the experiencer and tend to leave one, as with the woman I met in Colorado, with a persisting sense of existential dread about both life and death.

In reviewing the few cases Greyson and Bush had adduced for these experiences, I was struck with the fact that the preponderance of them involved women in childbirth who had been given anesthetics. Building on this slender data base, I ventured the hypothesis that "a disproportionate number of these experiences would involve the use of anesthetics, and that possibly they would be more likely to be reported by women" (Ring, 1994a, p. 21).

An examination of the sheaf of papers from Zacny disclosed further unequivocal empirical evidence for both of these propositions. Accordingly, as a consequence of my reading this material, I am now even more convinced of the validity of my earlier hypothesis and would like to share here some of this new evidence. Furthermore, in light of these findings, I believe it may now be justified to regard this type of experience differently than earlier conceptions (including my own) proposed, and to argue that, for all its horror, it is not a true NDE after all.

In my earlier article, I used one of Greyson and Bush's cases as a prototype of this kind of frightening NDE. It concerned a 28-yearold woman who, during a protracted delivery of her second child, had an experience in which she found herself propelled as if into a darkened outer space at tremendous speed (just as did the woman I spoke to in Colorado, by the way). Once in this realm, she encountered a small cluster of black-and-white circles, which alternated in color as they clicked rapidly from one to another. As they did so, voices mocked her, telling her that her entire life was an illusion, 
that it was nothing but a joke, and that she was simply allowed to imagine it. The experience left her with an acute sense of terror and existential dread.

In view of Zacny's findings, however, this case now appears to have even more significance as a prototype than I originally thought, since it turns out to have involved an administration of nitrous oxide. In fact, Zacny's collection of cases showed that this woman's experience is fairly typical of those reported by women in childbirth who have also been given nitrous oxide for anesthetic purposes.

In one Swedish study, for instance, all six women who were treated with nitrous oxide alone in connection with caesarean sections recalled "vivid and terrifying dreams during anesthesia . . . when interviewed one week later" (Bergström and Bernstein, 1968, p. 541). In some cases, these disturbing episodes left psychic scars that were apparent at least a year afterward. Here are just a few sample reactions to such administrations of nitrous oxide.

A 32-two-year-old woman said she had "dreadful dreams" in which

unknown people in a pop band repeatedly played the same sequence with continuously increasing volume. Suddenly, the noise stopped, and the patient felt frightened and sensed the destruction of both herself and her child. . . . A year later she was still almost daily tormented by the fear associated with the dream. ... Sensations were often precipitated by certain "electronic" sounds and rapidly changing pictures in television programs. (Bergström and Bernstein, 1968 , p. 541)

A 23-three-year-old mother of a premature baby "dreamed she was torn to pieces during heavy pains. Simultaneously, she heard rhythmic sounds. She said she would avoid this frightening experience in the future" (Bergström and Bernstein, 1968, p. 541). Another woman saw a "big white wall with black dots of different sizes, which fused to a black surface" (Bergström and Bernstein, 1968, p. 541). She later likened the experience to what she had heard about LSD intoxication. Finally, a 31-one-year-old woman described

a dreadful dream in which she was as a cog in a slowly rotating cogwheel of the universe, ruled over by a derisive executioner. . . . Each time her cog gripped she felt an insufferable pain and heard a crashing sound. The universe was blown up in a chaos of pain. (Bergström and Bernstein, 1968, p. 542)

Later, when she awoke, "she still believed she was in the dream world" (Bergström and Bernstein, 1968, p. 542) and at night she could not close her eyes lest she have frightening dreams. Six weeks 
later, she was still deeply troubled by this episode. "On such occasions she was in a cold sweat and filled with mortal fear and the belief that she was going insane" (Bergström and Bernstein, 1968, p. 542). This woman eventually needed psychiatric care and, though she slowly recovered, a year later this experience and its sequelae continued to agitate her.

Reading these accounts, one is impressed with the regularity of a certain type of unnerving rhythmic repetition of noises or of alternating images that appear menacing, as with my prototypic case where black-and-white circles flashed rapidly back and forth. Another such case is provided in the following testimony from a dental patient, supplemented with a note by the man's dentist (Evans, 1943). His narrative is extended and complex, however, and I will only be able to quote a few relevant portions here.

Having received nitrous oxide, as well as an inhalation of Trilene and, later, ether, the patient reported hearing a buzzing sound as the gas was being administered. Soon thereafter, he had an experience for which he gave this simile:

Imagine a huge disc covered with concentric blue and white circles, like a huge firing target. Then think of this as revolving at great speed and retreating and advancing with uncanny regularity. There was nothing else. The whole field of the mind's vision was filled with those circles that sped away into the distance and dwindled to a mere point. Then, just when that remote speck seemed to vanish altogether, it would grow again and resolve itself into the same pattern, but this time racing toward me with incredible speed. Backwards, forwards, backwards, forwards. (Evans, 1943, p. 121)

For this man, these circles seemed to hold the clue to the mystery of life itself and had for him a strange, almost impersonal, beauty. At the same time, however, he appeared to have found the sheer, unceasing repetition of these circles almost soulless and maniacally mechanical, and began to protest

when I found life reduced in its last analysis to this infallible clockwork. What about the courage of human hearts, and the love of God? But no answer was forthcoming from those silent whirling circles. Suddenly, the circles began to revolve at a greater speed, and retreated and advanced with an ever-increasing momentum. . . . I could see the inevitable end of this madness, and somewhere in my soul there must have been a great terror. (Evans, 1943, p. 122)

This motif of alternating or clicking circles that we have already encountered in some of these anesthetically-induced experiences oc- 
curs once more in another case that was briefly described to me by a physician, Pamela Kircher, on the same visit to Colorado where I acquired the Zacny papers. After I had read the latter, I called Kircher to ask her if she could give me a more complete account of this incident. She kindly obliged me, and this is the story she related to me over the telephone, which I took down verbatim:

A woman, who was about 30 years old when she spoke to Kircher, recalled a terrifying event from her childhood. When she was 13 , she decided to inhale some "PAM," a popular alcohol-based aerosol cooking spray. Her intention, she told Kircher, was simply to "get high."

She got more than she bargained for, however, as a friend attested that during this episode the young girl turned white and her lips became blue. Inwardly, she initially had what she termed an "Alice in Wonderland" experience with interesting mazes. Immediately afterward, though, her inner world took a drastically different and far more disturbing turn. To quote Kircher directly:

Then she ... found herself being sucked into a yellow cone with a red circular area at the bottom. She felt tight as she was being sucked down. She felt she was dead and didn't want to be there.

She experienced a feeling of being in a void. The only thing present was something like a weather vane, with a white circle which reversed to a black circle as it turned back and forth, with a clicking sound. It felt to her as if this were going to go on for a very long time. She heard "click, click" over and over again. It was very slow: "click" ... . "click" ... "click." Monotonous.

Her feeling was that she would be confined to this void for eternity. When she felt the full impact of the eternal isolation, she pulled all of her energy together, screamed "No!" to the universe, and with a tremendous burst of energy found herself slammed back into her body. (P. Kircher, personal communication, October 21, 1994)

In recalling this incident, the woman informed Kircher that no cardiopulmonary resuscitation had been performed, and that her recovery was spontaneous and self-willed.

Although the effects of nitrous oxide and similar inhalants are far more complex and variable than I have the space to indicate here, there seems to be little doubt that for many patients, and predominantly for women, its use, especially when unalloyed with barbiturates (Bergström and Bernstein, 1968), can give rise to a very distressing and distinctive type of experience of existential meaninglessness, marked by recurrent features such as those I have noted.

One final case of this sort came to my attention just as I was about to complete this article. A researcher named Gracia Fay Ell- 
wood, now in her mid-50s, wrote to me concerning a terrifying experience she had had when she was approximately 10 years old. Like that of Evans, her episode was triggered by the use of an inhalant in connection with dental work, although she is not sure exactly what anesthetic she was required to inhale. In any event, as the mask was placed over my informant's nose, she found the effect increasingly unpleasant, and also noticed that her sense of time had grown distorted. In consequence, the conversation of the dental team seemed speeded up and became unintelligible, adding to her distress. "But worse than that," Ellwood recalled,

I found myself in the presence of a great metallic wheel (or wheels) spinning rapidly. At the top of each revolution there was a tremendous crash as though a barrier was struck, but this didn't stop the spinning. The wheels were unpleasant but it was the terrible noise that made me frantic to get away. At some point, I pulled at the mask and tried to get it off, but [they] wouldn't let me take it off. (G. F. Ellwood, personal communication, October 20, 1994)

Again, we see the familiar anesthetic pattern of rotating devices, aversive noise, and generally mounting anxiety, unrelieved by any sense of meaning. In this instance, these effects seem to have been further compounded by the incomprehensible babble of the dental team as well as, according to Ellwood, a distinctive "mechanical and soulless" quality to her experience.

Finally, in regard to the second supposition of my original hypothesis, one may ask if, apart from these anecdotal cases consisting entirely of women with the lone exception of Evans, there is any systematic evidence that women in general are particularly adversely affected by nitrous oxide. There is, and some of it derives from studies that Zacny himself has helped to carry out. For example, in one recent such investigation of the effects of nitrous oxide in normal volunteers (Dohrn, Lichtor, Finn, Uitvlugt, Coalson, Rupani, de Wit, and Zacny, 1992), it was found that women reported more dysphoria and more somatic symptoms than men, and that the only patients who did not like a $\mathbf{4 0}$ percent concentration of nitrous oxide were women. Moreover, in an earlier study (Rosenberg, 1974), it was also observed that women responded differently to the inhalation of 40 to 80 percent nitrous oxide than did men. Specifically, as summarized by Cathleen Dohrn, Lance Lichtor, R. S. Finn, Anna Uitvlugt, Dennis Coalson, G. Rupani, Harriet de Wit, and Zacny, "females tended to find the inhalation unpleasant while males tended to find the experience pleasant" $(1992$, p. 28$)$. The reasons for these sex differences 
are still obscure, but there does seem to be an empirical basis for them.

All in all, I believe the findings surveyed here bolster the argument that these frightening experiences are best understood as emergence reactions triggered by drugs, and not as true NDEs. This is not, however, to discount the subjective reality of these experiences, to gainsay their capacity to instill the most soul-wrenching and long-lasting feelings of horror, or even necessarily to question their possible ontological significance. Instead, I merely want to make the claim that these experiences should not be indiscriminately lumped with NDEs, even with those of a frightening cast.

These observations, as will be evident, help to bring back into salience a question that has never really received its due in the field of near-death studies. That question is, what do we really wish to signify by the term we all use so casually, "the near-death experience"? Perhaps instead of routinely labeling virtually any surgical or other drug-related occurrence that is associated with an unusual otherworldly state of consciousness an NDE, we should begin to specify and use more carefully certain criteria that would serve to define an NDE more precisely and thus give it an agreed-upon meaning. That way, we would be less likely in the future to confound the effects of certain drugs with NDEs as such.

\section{References}

Bergström, H., and Bernstein, K. (1968). Psychic reactions after analgesia with nitrous oxide for caesarean section. Lancet, 2, 541-542.

Dohrn, C. S., Lichtor, J. L., Finn, R. S., Uitvlugt, A., Coalson, D. W., Rupani, G., de Wit, H., and Zacny, J. P. (1992). Subjective and psychomotor effects of nitrous oxide in healthy volunteers. Behavioural Pharmacology, 3, 19-30.

Evans, D. I. (1943). A layman's account of "going under." British Journal of Anaesthesia, 18, 119-125.

Greyson, B., and Bush, N.E. (1992). Distressing near-death experiences. Psychiatry, $55,95-110$.

Ring, K. (1994a). Solving the riddle of frightening near-death experiences: Some testable hypotheses and a perspective based on $A$ course in miracles. Journal of Near. Death Studies, 13, 5-23.

Ring, K. (1994b). Frightening near-death experiences revisited: A commentary on responses to my paper by Christopher Bache and Nancy Evans Bush. Journal of NearDeath Studies, 13, 55-64.

Rosenberg, P. (1974). The effect of $\mathrm{N}_{2} \mathrm{O}$-oxygen inhalation on subjective experiences of healthy young adults. Annales Chirurgiae et Gynaecologiae Fenniae, 63, 500-504. 
